\title{
AS RELAÇÕES IMPERADOR / GUARDA PRETORIANA NA OBRA DE HERODIANO
}

Ana Teresa Marques Gonçalves

Universidade de São Paulo

Resumo: Neste Trabalho, procuramos analisar as relações estabelecidas entre os Imperadores Romanos, a Guarda Pretoriana e seus respectivos Prefeitos do Pretório, de Marco Aurélio aos Gordianos. Utilisamos a obra de Herodiano: "História do Império Romano depois de Marco Aurélio", onde o autor fornece informą̧óes interessantes para a reflexão sobre algumas questóes relativas a passagem do II para o III século d.C., como as crises ligadas à sucessão imperial, o relacionamento das Coortes Pretorianas com as legióes estacionadas nas fronteiras $e$ as Coortes Urbanas, e os poderes delegados pelos governantes aos seus Prefeitos.

Palavras-chave: História Romana, Guarda Pretoriana, Herodiano.

A passagem do segundo para o terceiro século d.C. marca um momento de inflexão no cenário sócio-político romano. A morte de Cômodo e a crise sucessória que se instala logo a seguir inauguram um período conturbado ${ }^{1}$, classificado de diversas maneiras, segundo as posiçōes metodologicas assumidas pelos autores que 0 estudaram.

Identificado como transição de um Império Senatorial para um Império Militar (GAGÉ, 1964, p.249); como passagem do principado para o Dominato (HOM0, 1927, pp.288-332); ou como ápice de uma crise generalizada que desencadeou uma profunda mudança na estrutura social romana (ALFÖLDY, 1989, pp.172-199), tal momento histórico foi indubitavelmente um período de transformação do contexto político romano.

Observamos que existe uma unanimidade na historiografia no sentido de enfatizar o valor da participação dos exércitos na tomada de decisōes políticas, referentes principalmente à sucessão imperial. Processos de burocratização, especialização de funções, centralização e militarização do poder já vinham ocorrendo desde o período dos Antoninos, mas múltiplos fatores levaram a um acirramento de tais processos durante e apos o período dos Severos.

Neste trabalho, limitamos nossa problemática às relações que se estabeleceram entre duas forças políticas, cuja interação muito contribuiu para promover as transformações supra-citadas: o Imperador e a Guarda Pretoriana. Ateremo-nos ao período cronológico que se estende da morte de Marco Aurélio à ascensão de Gordiano III.

1. Segundo Jean Gagé (GAGÉ, 1964, p.249), após o governo de Cômodo rompeu-se definitivamente o entendimento entre o poder imperial $\theta$ a aristocracia senatorial, abrindo espaços para mudanças na máquina do governo e para a ascensão da ordem equestre. 
Para tanto, utilizaremos a obra de Herodiano: "História do Império Romano após Marco Aurélio", que abarca o período a ser analisado. Esta obra junto com a "História Romana" de Dion Cássio e com a "História Augusta" formam um "corpus" de fontes textuais fundamental para a compreensão do momento enfocado.

Muito pouco se sabe sobre a vida particular e pública de Herodiano, o que faz com que os historiadores que trabalham com o seu discurso estejam sempre situados no campo das hipóteses. Atualmente acredita-se que ele tenha nascido por volta de 180 d.C. na região oriental do Império ${ }^{2}$, pois escreveu em grego, e que tenha falecido na mesma região em torno do ano de $250 \mathrm{~d}$.C. Sua condição social é incerta, mas em sua própria obra ele afirma que exerceu várias funções imperiais ou públicas, durante as quais foi testemunha de vários fatos que constituiram o sujeito de sua narrativa. (Herod. 1.2.5). Seu trabalho consta de oito livros que devem ter sido publicados separadamente durante o reinado de Filipe, o Arabe, possivelmente em 248 d.C.

Nota-se que 0 autor produz um discurso onde reitera a todo instante 0 ponto de vista senatorial, ordem da qual obteve um possivel patronato, que the possibilitou escrever e publicar a obra em questão, e que foi o. seu provável públicoleitor. Pode-se inferir esta vinculação de Herodiano com os senadores pela existência de diversạs passagens nas quais ele defende a organização de governos aristocráticos, capazes de evitar os perigos de um poder pessoal ilimitado e absoluto que tenderia a se inclinar para a constituição de uma tirania (Herod. I.2.2; II.6.2; II.3.10; II.14.3; V.1.4; VII.10.2).

Assim sendo, Herodiano critica em várias passagens a intromissão constante da Guarda Pretoriana e de seus Prefeitos nos designios imperiais, principalmente quando passam a interferir diretamente na proclamação e na deposição dos Imperadores, gerando distúrbios no processo sucessório (Herod. II.4.4 e II.10.2-5).

A origem de uma guarda de honra permanente, diretamente ligada a um general, remonta aos tempos republicanos. 0 primeiro cidadão romano a organizar a sua "Cohors Praetoria" foi Cipiāo Emiliano, que reuniu ao seu redor quinhentos clientes e amigos. Tal prática se afirmou e se ampliou no período das guerras civis, que marcaram o final da República. Quando Augusto foi proclamado "Imperator", fixou parte dos soldados que 0 apoiavam num quartel general em Roma que, enquanto residência militar do soberano, recebeu a denominação de "Praetorium" 3 . Ele separou seus homens em nove "cohortes" 4 , sendo que três permaneceram acampadas em Roma enquanto as outras foram espalhadas pelas diversas residências imperiais existentes na Itália (DAREMBERG et SAGLIO, s.d., pp.632639).

2. Na Grécia, na Siria ou na Ásia Menor.

3. Desde os primórdios das conquistas republicanas, chama-se "Praetorium" a parte central do acampamento militar, onde se localiza a tenda do general comandante. Quando o Imperador torna-se 0 chefe de todas as legióes e fixa residencia em Roma, lá constrói a sua morada militar que toma o nome de "Praetorium" (DAREMBERG et SAGLI0, s.d., pp. 640-642).

4. "Cohors" é o nome dado a uma tropa de infantaria do exército romano. Ela agrupa em média quinhentos homens. Cada legião abarcava dez "cohortes". As que nos interessam neste trabalho são as organizadas em vista de um serviço especial, como as "Cohortes Praetoriae", "Urbanae" e "Vigilum" (DAREMBERG et SAGLIO, s.d., pp. 1287-1289). 
Foi Sejano quem pela primeira vez reuniu todas as "cohortes" num só acampamento dentro da capital do Império. Por se acomodarem no interior do "Praetorium" foram denominadas "Cohortes Praetoriae". Inicialmente, como demonstra Herodiano, sua funçāo era proteger o Imperador, acompanhando-o por todos os lugares e em todas as ocasiōes, em tempos de paz ou de guerra (Herod. II.5.6. e IV.5.1). Eram também as "cohortes" que estavam ao lado do "Princeps" nas cerimônias oficiais (Herod. II.13.2 e V.5.9-10), nos funerais, nas viagens e expedições militares empreendidas fora da Itália (Herod. IV.7.3; IV.9.6; VI.8.7; VI.9.2 e VIII.1.2). Além disso, eram responsáveis por garantirem a segurança do Palácio imperial (Herod.I.12.6; II.6.4 e V.4.8).

Com o passar do tempo, elas foram adquirindo novas funções. De protetoras da pessoa do Imperador, passaram a ser encaradas como responsáveis por velarem por tudo o que dizia respeito ao cargo imperial (CIZEK, 1990, p.295). Assim, tomaram para si as funções de acalmar as sediçōes na Itália e nas províncias (Herod. VII.3.3), montar guarda nos espetáculos (Herod.I.12.6-9), proteger os membros da familia imperial, vigiar prisioneiros considerados importantes e servir como um reservatório de funcionários para o governo (JACQUES et SCHEID, 1990, p.133).

0 regulamento imperial determinava que todas as legiões permanentes pertencentes a um campo fixo deveriam ser comandadas por um Prefeito do Campo. No caso da Guarda Pretoriana, ela era dirigida pelo "Praefectus Praetorio". Ele era um funcionário imperial, não um magistrado, pois não detinha nenhum poder próprio. Seus poderes resultavam unicamente de uma delegação que the era concedida pelo "Princeps". Deste modo, recebia um "salarium" e não tinha um tempo fixo de mandato, podendo ser retirado do cargo a qualquer momento, dependendo dos interesses e das necessidades politicas do Imperador (CIZEK, 1990, pp.294295).

Seu poder era primeiramente apenas militar, mas a partir do momento em que o imperador foi conquistando mais poderes, ele foi delegando um número maior de tarefas aos seus subordinados (HOWE, 1942, p.15). Então, ao longo do segundo e do terceiro séculos, o Prefeito do Pretório adquiriu o comando extraordinário de tropas fora da Itália, passou a controlar o dinheiro arrecadado com a "annona" militar, a participar do "consilium principis" (PASSERINI, 1939, pp.259-263), a exercer o poder judicial em última instância e a auxiliar o Imperador na administração do Império, cuidando inclusive de sua correspondência privada $e$ secreta (Herod. VII.6.6). Suas tarefas se ampliaram de tal forma que alguns historiadores o identificaram como um vice-Imperador (HOWE, 1942, pp.11-12) ${ }^{5}$. Todavia, tratava-se de uma Prefeitura que devia ser ocupada, em caráter de colegialidade (Herod. I.9.10), por dois membros da ordem equestre ${ }^{6}$.

Enquanto membros proeminentes da ordem equestre, vinculados diretamente ao Imperador, os Prefeitos tiveram seus poderes fortalecidos numa tentativa de se enfraquecer as possibilidades de mando do Senado e do Prefeito da Cidade de Roma, numa oposição direta às prerrogativas políticas até então detidas

5. Posição esta defendida também por HOMO, 1927, p. 371 e criticada por DURRY, 1938, p. 171.

6. Em alguns momentos de exceção tais regras não foram seguidas, existindo apenas um ou até três Prefeitos com poderes delegados ao mesmo tempo e sendo escolhidos entre libertos ou senadores. 
pela camada senatorial, fazendo com que o Imperador tivesse ao seu lado homens fortes e detentores de sua total confiança (ALFÖLDY, 1989, p.181) ${ }^{7}$.

Destarte, enquanto uma fonte senatorial, Herodiano apresenta os Prefeitos de uma forma dicotômica e maniquelsta, da mesma maneira como constrói as figuras dos "Principes". Há os bons Prefeitos, que são leais não só ao Imperador, mas principalmente à Pátria, como Leto, que livrou Roma do tirânico Cômodo (Herod. I.16.5; I.17.4-11; II.1.3 e II.2.1-5), ou como Advento, que recusou a púrpura imperial após a morte de Caracala (Herod. IV.12.1 e IV.14.2). E há os maus Prefeitos, como Perênio (Herod. 1.8.1-8), Cleandro (Herod. I.12.3-5), Plauciano (Herod. III.10.6-7 e III.11.1-3) e o próprio Macrino, que se transformou no primeiro Imperador de origem equestre (Herod. V.1-7), que são mostrados como seres sediciosos, promotores de intrigas e que se deixaram envolver por suas ambições pessoais.

Interessante enfatizar, porém, que os quatro Prefeitos acima citados estavam já bastante afastados de suas tropas, ocupando um cargo cada vez mais politico do que militar, quando resolveram dar vazão às suas ambiçōes pessoais, tanto que as tropas não se rebelaram após as suas deposicões e assassinatos.

Vejamos os casos. Perênio, segundo o relato de Herodiano, era um excelente militar que se aproveitou da inexperiência de Cômodo e do cargo que ocupava para assumir o governo do Império. Buscou 0 apoio do exército ilírio na conjuração que armou contra Cômodo, mas acabou sendo descoberto e morto, sem que os Pretorianos fizessem um so movimento em sua defesa. Já Cleandro contou com 0 apoio somente dos cavaleiros da guarda imperial (Herod. 1.12.6), era odiado pela "plebs" e sua sedição foi denunciada por uma irmã de Cômodo. Ele acabou sendo assassinado e, novamente, os Pretorianos não se rebelaram em defesa de seu Prefeito. Plauciano, por sua vez, é descrito como um homem humilde que chegou ao cargo por benevolência de Septímio Severo. Tinha a consideração dos soldados (Herod. III.11.2), mas foi traído pelo proprio tribuno encarregado por ele de matar o Imperador. Foi a guarda do palácio que o prendeu e o matou (Herod. III.12.9). No que se refere a Macrino, foi a segunda opção num momento muito delicado para o Império e subiu ao poder apoiado não só pelos Pretorianos, mas principalmente pelas legiões que lutavam contra os Partos (Herod. IV.14.1-4). Herodiano ressalta que ele conseguiu o Império não tanto pelo afeto e confiança dos soldados como pela necessidade e exigências do momento (Herod. IV.14.3). Um ano depois, ele foi obrigado a fugir perseguido pelos própros Pretorianos, que passaram a apoiar Heliogábalo, apresentado por Julia Mesa como filho de Caracala (Herod. V.3.10 e V.4.8-10).

Portanto, torna-se importante separar as rebeliōes da Guarda Pretoriana, como a que derrubou Pertinax do poder (Herod. II.4.4) das sedições promovidas por

7. 0 Senado conservava ainda, neste momento, um tal prestíio que quando os cavaleiros passam a integrar este conselho, não săo os senadores que desaparecem, mas os próprios cavaleiros que buscam se moldar às caracteristicas da aristocracia burocrática que está em formaçăo. Tanto que, vários Prefeitos do Pretório, posto máximo a ser atingido por um equestre, săo contemplados com a concessão da "ornamenta praetoria" ou "consularia", com a "adlectio inter consulares" ou "praetores", ou com a "dignitas senatoria", passando mesmo a se utilizar do tftulo de "uir clarissimus", apenas aplicado aos senadores. Assim, as carreiras senatorial e equestre se aproximaram paulatinamente, até que com Constantino a fusão se tornou completa (DURRY, 1938, pp. 176-181) 
alguns Prefeitos, que nem sempre obtiveram um apoio direto das "cohortes", como tentamos demonstrar anteriormente. Recordamo-nos mais facilmente dos Prefeitos apresentados pela historiografia senatorial produzida no período como traidores, mas eles representaram mais uma exceção do que uma regra. Lembremo-nos das figuras de Juliano (Prefeito de Macrino) (Herod. V.4.3-4) e de Vitaliano (Prefeito de Maximino) (Herod. VII.6.4) que morreram lutando pelos seus Imperadores. Acrescente-se a isto o fato de que nenhum Imperador abriu mão de manter ao seu redor uma Guarda Pretoriana, buscando sempre adaptá-la às suas necessidades.

Desta forma, notamos que a Guarda Pretoriana, mais do que uma mera parte do exército, se constitui numa tropa de elite, que se distinguia das outras "cohortes" por meio das relações especlficas que mantinha com o imperador e dos privilégios que detinha. Até o governo de Septímio Severo, ela era formada apenas por cidadãos romanos recrutados somente na Itália, que prestavam um serviço de dezesseis anos e que recebiam um soldo bastante superior ao dos legionários. Deste modo, as legiōes alocadas nas fronteiras formavam uma força sócio-politica peculiar que se diferenciava em muitos aspectos da representada pela Guarda Pretoriana, inclusive em relação aos interesses que representavam na luta pelo poder, apesar de ambas serem formadas por homens em armas.

Esta dicotomia exército nas fronteiras / Guarda Pretoriana, no que concerne à relação com o Imperador, pode ser constatada em várias passagens de Herodiano. Entre elas destacarlamos os periodos governamentais de Pertinax (Herod. II.2.1 e II.4.4) e de Didio Juliano (Herod. II.6.3-6), momento no qual 0 autor estudado identifica o inicio do desrespeito dos soldados pela dignidade imperial e a sua opção pelo ganho fácil e pela indisciplina (Herod. II.6.14). Entretanto, acreditamos que tenha sido a mudança de concepção da tarefa da Guarda Pretoriana - de protetora da pessoa do Imperador para zeladora do cargo imperial - que tenha dado às "cohortes" as prerrogativas necessárias para vender tal cargo a Dilio Juliano.

Esta situação se acirrou no governo de Septimio Severo, que chegou a fazer um discurso destinado a inflamar os ânimos de suas legiōes contra as "cohortes" Pretorianas (Herod. II.10.2-6) e que promoveu uma profunda reforma nesta Guarda (Herod. II.13.6-14), procurando enfraquecê-la. Antes de entrar em Roma, Severo ordenou que a Guarda Pretoriana se desarmasse e que se retirasse para um acampamento localizado a cem milhas de Roma. Logo a seguir, modificou profundamente o seu recrutamento, decidindo que as "cohortes" Pretorianas seriam formadas por legionários vindos de todo o Império, sendo convocados pelo próprio Imperador, que substitula, assim, 0 sistema dos engajamentos voluntários. Ele pretendia por intermédio deste expediente substituir os italianos e alguns poucos provinciais mais romanizados por soldados devotados a sua pessoa, Ihes oferecendo como recompensa por esta lealdade a entrada nas fileiras pretorianas, mais bem pagas do que as outras tropas. Além disso, Severo reforçou os "Equites Singulares", organizou uma tropa de policia casemada em Roma (os "Peregrini") e estabeleceu nos Montes Albanos, proximos a Roma, uma das três novas legiões por ele criadas chefiadas por comandantes equestres. Buscou, desta forma, aumentar sua segurança pessoal e vincular a força politica da Guarda Pretoriana à sua própria força política. Mediante uma análise destas medidas de Septimio Severo, podemos observar que a Guarda Pretoriana voltou a assumir o caráter de defensora do Imperador e entra no bojo do processo de fortalecimento das províncias face ao poder decisório até então detido pela Itália. 
Quanto ao período de Macrino, A Guarda Pretoriana e as legiões provinciais voltaram a se posicionar politicamente de lados contrários em vários momentos (Herod. V.4.2). Situação esta que se prolongou no governo de Alexandre Severo que, por sua vez, contou com 0 apoio dos Pretorianos, mas enfrentou rebeliōes promovidas pelas legiōes estacionadas no Egito e na Siria (Herod. VI.4.7) e acabou morrendo assassinado pelos soldados durante uma campanha militar. No que se refere a Maximino, ele obteve 0 apoio das legiōes da Panônia e da Trácia (Herod. VIII.6.1), mas foi derrubado do poder com a ajuda dos Pretorianos (Herod. VIII.5.9), que assassinaram também o seu Prefeito do Pretório. Com relação a Máximo e Balbino, eles tentaram conseguir 0 apoio das tropas germånicas. Contudo, acabaram sendo mortos pelos Pretorianos, que logo depois proclamaram um menino de treze anos, Gordiano III, o novo detentor do trono imperial (Herod. VIII.8.5-8).

Observamos, portanto, que cada Imperador que chega ao poder busca se relacionar de uma forma especifica com as forças sócio-politicas que o cercam, procurando obter um grupo de apoio que garanta a legitimidade de sua autoridade. Para isso utilizaram múltiplos expedientes, sendo que os mais comuns foram a distribuição de dinheiro aos soldados (Herod. 1.5.1) e de viveres ao povo.

Para concluir, gostariamos de enfatizar que de uma milícia formada por amigos e clientes de um general na República, as "cohortes" Pretorianas se transformaram numa força política decisiva, ao longo do segundo e do terceiro século d.C. Tornaram -se tăo temidas que acabaram sendo desarticuladas no século IV d.C., durante 0 governo de Constantino. 0 cargo de Prefeito do Pretório foi mantido, mas passou a ter apenas atribuições civis. No lugar da Guarda, Constantino organizou um grupamento de "Protectores Domestici", escolhidos entre oficiais superiores advindos das legiōes. Retomou-se o principio de que o Imperador deveria possuir ao seu redor uma millcia armada para proteger a sua pessoa, mas este grupo não deveria possuir nenhuma força politica própria como por algum tempo deteve a suprimida Guarda Pretoriana. Vemos, assim, que durante todo 0 Império, os governantes mantiveram sempre um grupo de homens armados em torno de si, cuja função primordial era garantir a sua segurança. Contudo, foi somente no segundo e no terceiro séculos que este grupo conquistou uma posição de força política atuante no seu relacionamento com o Imperador.

RÉsume: Dans ce travail, on cherche analiser les rélations établies entre les Empereurs Romains, la Garde Prétorienne et leurs respectives Préfets du Prétoire, de Marc-Aurèle aux Gordiens. On utilise l'ouvre d'Hérodien: "Histoire de l'Empire Romain après MarcAurèle", où l'auteur fournit informations intéressantes à réflexion sur quelques questions relatives à passage du $\|^{\circ}$ au $11^{\circ}$ siècle de notre ère, comme les crises liées à succession impérial, la relation des Cohortes Prétoriennes avec les légions stationnées aux frontières et les Cohortes Urbaines, et les pouvoirs délégués par les gouvernants aux leurs Préfets. 
BiBLIOGRAFIA

ALFöLDY, G. A História Social de Roma. Lisboa: Presença, 1989.

CIZEK, E. Mentalités et Institutions Politiques Romaines. Paris: Fayard, 1990.

DAREMBERG, Ch. et SAGLIO, M. E. Dictionnaire des Antiquités Gecques et Romaines. Paris: Hachette, s.d.

DURRY, M. Les Cohortes Prétoriennes. Paris: E. de Boccard, 1938.

GAGE, J. Les Classes Sociales dans I'Empire Romain. Paris: Payot, 1964.

HERODIANO. Historia del Imperio Romano después de Marco Aurelio. Traducción y notas por Juan J. Torres Esbarranch. Madrid: Gredos, 1985.

HÉRODIEN. Histoire de l'Empire Romain après Marc-Aurèle. Traduit et Comenté par Denis Roques. Paris: Les Belles Lettres, 1990.

HOMO, L. Les Institutions Politiques Romaines. Paris: Albin Michel, 1927

HOWE, L. L. The Pretorian Prefect from Commodus to Diocletian. Chicago: University of Chicago Press, 1942.

JACQUES, F. et SCHEID, J. Rome et l'Intégration de l'Empire. Paris: PUF, 1990.

LE GALL, J. et LE GLAY, M. L'Empire Romain. Paris: PUF, 1989.

PASSERINI, A. Le Coorte Pretorie. Roma: Angelo Signorelli, 1939.

TURCAN, R. Vivre à la Cour des Césars. Paris: Les Belles Lettres, 1987. 